\title{
COMO SÃO POSSÍVEIS DEVERES DE VIRTUDE EM KANT?
}

- RESUMO: Este trabalho pretende mostrar em que consiste e qual é a importância de se investigar e oferecer uma resposta ao problema da possibilidade dos deveres de virtude. Sendo assim, faremos, em primeiro lugar, uma aproximação do problema da possibilidade dos deveres de virtude a partir de problemas que dizem respeito a outros juízos sintéticos a priori para, em seguida, indicarmos os requisitos que devem ser cumpridos pelos deveres de virtude para que sejam considerados possíveis. Esta investigação está comprometida com a leitura semântica de Loparic.

- PALAVRAS-CHAVE: Kant, semântica, deveres de virtude.

De acordo com Kant, à razão humana, devido a sua própria natureza, pertencem questões que "ultrapassam completamente as suas possibilidades" (KANT, 1983, A VII), ou seja, questões totalmente insolúveis que fazem com que ela incorra em devaneios e contradições. Estes, por sua vez, produzem um "clima" de suspeita acerca das pretensões da razão fundar algum conhecimento válido. A única solução encontrada por Kant, para combater o ceticismo que brota deste quadro, é a atitude crítica. A crítica exige que se suspenda o juízo até que se decidam questões preliminares, a saber, questões acerca da fundamentação e da "determinação das regras e limites do uso" da faculdade de conhecer, ou melhor, a investigação acerca dos li-

1 Doutorando no Programa de Pós-Graduação em Filosofia da Universidade de Campinas-Unicamp sob orientação de Zeljko Loparic e com auxílio da Capes. Artigo recebido em jan/06 e aprovado para publicação em nov/06. 
mites do próprio conhecimento a priori válido. Isto constitui a filosofia transcendental, pois ela se preocupa menos com os objetos do que com o modo de os conhecer.

Para Kant todo conhecimento é constituído por juízos. Tendo em vista que apenas um juízo sintético "acrescenta ao conceito do sujeito um predicado que de modo algum pode ser pensado nesse sujeito e que não poderia ter sido extraído dele por nenhuma análise" (idem, B 11), e que toda ciência pretende ser universalmente válida, este juízo, além de sintético, também tem ser a priori. Assim sendo, diz Kant, "o verdadeiro problema da razão pura está contido na seguinte pergunta: como são possíveis juízos sintéticos a priori?" (idem, B 19). A solução deste problema decide, por sua vez, o problema da validade do conhecimento a priori ${ }^{2}$ pois a classe das proposições ${ }^{3}$ a priori solúveis equivale à classe das proposições sintéticas a priori possíveis (cf. LOPARIC, 2000, p.5). Por esse motivo é extremamente necessário saber quais são as condições de possibilidade destas proposições.

É importante notar, todavia, que, para Kant, a razão não opera apenas teoricamente (buscando conhecer objetos), mas também opera praticamente (buscando determinar a máxima das ações), entre outras operações. Cada uma destas operações faz uso de juízos sintéticos a priori, e devem ser investigados quanto a sua possibilidade. Este quadro aponta para o fato de que a investigação acerca da possibilidade dos juízos sintéticos a priori, que na primeira Crítica se remetia apenas aos juízos teóricos, foi consideravelmente ampliada ao longo dos escritos kantianos. Portanto, ao final, já contamos com juízos (ou proposições) moral-práticos, técnico-práticos (KANT, 1983, KU, pp.XII-XV), jurídico-práticos (idem, MS-R, p.63), estéticos (ou de gosto) (idem, KU, p.4, pp.131-52), históricos (idem, SF, pp.132-3), entre outros. Logo, o problema da filosofia transcendental se amplia e se transforma na investigação da possibilidade de juízos sintéticos a priori em geral.

Quando se fala em investigação da possibilidade destes juízos, o que se tem em mente não é apenas a sua possibilidade lógica (condicionada pelo princípio de não-contradição), mas também a realidade objetiva dos mesmos, ou seja, a sua apresentação (Darstellung). O não cumprimento desta exigência faz com que o conceito, fundado sobre um tal juízo, seja vazio (ou, sem sentido), devendo conseqüentemente ser descartado a fim de que não cause prejuízos ao sistema.

2 O qual é constituído apenas de juízos (ou proposições) solúveis e que contenham conceitos decidíveis.

3 Kant em muitos momentos não fala em proposições (Sätze), mas apenas em juízos (Urteile). Em outros momentos, ao contrário, fala apenas das proposições e não dos juízos. Contudo, apesar de Kant tê-los distinguido na Lógica Jäsche (KANT, 1983, LJ, § 30), usamos estes termos de forma indistinta, como o próprio Kant faz na Crítica da Razão Pura. Nisto seguimos Loparic (2000, p.9). 
O campo prático é o que mais apresenta dificuldades quanto à possibilidade e validade de seus conceitos, justamente pelo fato de, geralmente, a apresentação do conceito não ser possível de modo direto. Esta dificuldade fez com que Kant despendesse grande tempo e esforço para o tema do agir humano (isto é, o campo prático), ${ }^{4}$ tendo escrito três obras totalmente dedicadas a moral (ou os costumes) durante seu "período crítico". Contudo, é possível notar um considerável avanço em suas abordagens da problemática da possibilidade e validade dos juízos (ou proposições) entre Fundamentação da Metafísica dos Costumes (1785) e a Metafísica dos Costumes (1797).

Em 1785, na Fundamentação, ele empreendeu a "busca e fixação do princípio supremo da moralidade" (idem, GMS, p.19). O princípio supremo da moralidade é a autonomia da vontade, assegurada por meio do imperativo categórico (que é uma proposição sintética a priori que une a vontade humana a regra da universalização) (ibidem, p.85). Tal princípio requer que a realidade da idéia de liberdade seja demonstrada, uma vez que ela é a condição tanto para a vontade autônoma, quanto para o imperativo categórico. Kant chega ao final desta obra admitindo a impossibilidade de expor a realidade objetiva desta idéia fundamental e, por esta causa, deve valer "somente como pressuposto necessário da razão num ser que julga ter consciência duma vontade" (ibidem, p.111). Em outras palavras, ele chega ao final da obra com o problema totalmente indeciso e, de acordo com a semântica transcendental, um conceito que permanece indeciso (ou que não há decisão possível) é vazio (isto é, sem sentido) e, deve ser descartado. Entretanto, sendo este um problema fundamental da semântica moral, Kant não podia apenas deixar de lado o problema. Logo, ele posterga a decisão (ou resolução) deste problema para a Crítica da Razão Prática. Ao final da Fundamentação, Kant consegue apenas garantir a possibilidade lógica da lei, isto é, justificar, a fórmula do imperativo categórico (idem, KPV, p.13).

Na segunda Crítica (1788) a sua preocupação já era outra, a saber, demonstrar a vigência da razão prática (ou vontade) por meio de uma lei moral (ou imperativo categórico). Vigência esta entendida como capacidade de autodeterminar-se, o que supõe novamente o conceito de liberdade, pois esta é a condição sem a qual não é possível uma lei moral. Disto resultou uma nova investigação acerca da possibilidade dos juízos e conceitos envolvidos. Contudo, nesta obra, Kant já oferece uma decisão para o problema. A resposta consiste propriamente na determinação da realidade objetiva da lei moral por meio do fato da razão (consciência da lei que, conseqüentemente, produz um sentimento de respeito por esta lei) (cf. ibidem, pp.9-10, pp.49-50, p.52, p.53, p.67, p.69, pp.74-5). A lei é sensificada (ou efetivada)

4 Por ora, deixamos de lado a problemática jurídica e histórica que também pertence ao campo prático, pois nosso interesse aqui é apenas o agir ético-moral. 
por meio deste sentimento de respeito pela lei moral. Por conseguinte, a liberdade também obtém realidade objetiva por meio desta lei, devido à reciprocidade existente entre lei moral e liberdade, uma vez que não há lei moral sem liberdade, e não é possível "conhecer" a liberdade a não ser mediante a vigência da lei. A novidade apresentada por esta segunda Crítica consiste propriamente no fato de Kant ter constatado a necessidade de um novo campo de significação dos conceitos com regras distintas do campo teórico. Isto porque, em se tratando do campo prático, já não eram mais válidas as regras do campo teórico, tendo em vista que (como foi verificado na Fundamentação da metafísica dos costumes), não é possível obter objetos correspondentes aos conceitos práticos. Sendo assim, podemos afirmar, com Loparic, que Kant nesta segunda Crítica cria um novo campo de significação, a saber, o campo prático (das ações executáveis), em contraposição ao domínio teórico (dos objetos possíveis) (cf. LOPARIC, 2003, p.478).

Resta ainda elucidar algo deste campo moral-prático, a saber, as regras de aplicação da ética ao domínio sensível. Estes princípios são desenvolvidos por Kant na segunda parte de sua Metafísica dos Costumes, a Doutrina da Virtude. Nesta obra Kant pretende expor a aplicação da ética por meio de fins que são ao mesmo tempo deveres, ou seja, ética entendida como doutrina da virtude. Esta doutrina da virtude seria a própria aplicação da ética ao sensível, ou melhor, ela apresenta os princípios de aplicação da ética à antropologia.

O objetivo geral da Doutrina da Virtude, segundo Kant, é a conquista da sabedoria prática (KANT, 1983, MS-T, p.46). Sabedoria prática uma vez que ela consiste justamente na posse do homem de si mesmo. Ou, em outras palavras, autocontrole, conquistado por meio de uma constante autocoerção (Zwang). A conquista desta sabedoria nos remete a um sistema de fins (ibidem, p.5), os quais a posse é um dever ter (isto é, nos remete a deveres de virtude). A razão para isto é que esta sabedoria só pode ser alcançada mediante o cultivo da virtude, supondo uma espécie de treinamento moral. O cultivo é necessário porque o arbítrio humano é constantemente influenciado pelos fins da natureza (o prazer) a transgredir a lei moral. Portanto, é necessário que a razão legisladora impeça a influência destes fins da natureza "mediante um fim moral instaurado contra os fins da inclinação" (ibidem, p.4).

Este fim moral é um dever possuir. Pois, trata-se de um fim que tem de ser considerado ao mesmo tempo um dever. Este tipo de dever é denominado dever de virtude, e só pode pertencer à ética, já que diz respeito a uma legislação interior (autocoerção). ${ }^{5}$ Assim sendo, a validade deste tipo de de-

5 Uma coerção a fins ditada por outrem é algo que contradiz o próprio conceito de fim (cf. KANT, 1983, MS, p. 5). 
veres depende da possibilidade deste tipo de fins. Desta forma, o problema que se apresenta é saber "como é possível um tal fim"? (ibidem, p.6). Ou ainda, como são possíveis deveres de virtude?

Primeiro, é necessário saber do que falamos quando tratamos de um fim que é dever. A definição dada por Kant ao conceito de fim é a seguinte: "fim é um objeto do livre arbítrio cuja representação o determina para uma ação" (ibidem, p.11). A princípio, esta nova exigência "moral" pode parecer contraditória com tudo o que Kant havia dito anteriormente. Porém, é importante ressaltar que a moralidade da ação não é propriamente determinada mediante a representação do referido fim. A representação do fim determina apenas uma ação que funcionará como uma espécie de "antídoto moral" contra as inclinações contrárias a moralidade. A moralidade da ação em todo caso já terá sido determinada anteriormente, uma vez que ela reside na intenção com a qual se decidiu tornar deveres um tipo de fins. A intenção moral deve ser sempre aquela contida nas formulações que Kant oferece do imperativo categórico ainda em 1785: na universalização de máximas (de modo que estas possam se tornar leis universais da natureza), na humanidade como fim em si mesmo (e nunca como meio para outros fins) e na constituição de um reino de fins (de modo que todos os agentes morais estejam interligados). Estes preceitos estão contidos nos deveres de virtude para consigo e para com os outros. Os primeiros mandam perseguir, a cada momento, a perfeição pessoal; e, os segundos, mandam promover, a cada momento, a felicidade alheia.

A determinação deste tipo de fim se dá por meio da legislação interna. Este ato de determinar um fim é um imperativo categórico que liga um conceito de dever ao de um fim em geral (ibidem, p.12). Em outras palavras, um dever de virtude é um imperativo categórico (que, por sua vez, é um juízo sintético a priori). A sua importância consiste no fato de que "somente o conceito de um fim que é também um dever, um conceito que pertence exclusivamente à ética, estabelece uma lei para máximas de ações subordinando o fim subjetivo (que todos têm) ao fim objetivo (que todos devem tornar seu fim)" (ibidem, p.19).

A investigação acerca de sua possibilidade segue as regras semânticas de interpretação. De acordo com Loparic, a possibilidade das proposições sintéticas consta de uma condição formal e de duas condições semânticas de sua verdade ou falsidade objetivas, a saber: "A condição formal única é dada pelo princípio de não-contradição. (...). A primeira das condições semânticas requer, portanto, que todos os conceitos não-lógicos que ocorrem numa proposição sintética tenham referência e significado objetivos. A segunda das condições semânticas é satisfeita associando-se certas formas intuitivas de perceptos ou dados puros da imaginação, com formas lógicas de proposições (e com categorias)" (LOPARIC, 2000, pp.20-3). 
Dito de outra forma, referência significa apresentar o conceito. De acordo com Kant, toda apresentação de conceitos é esquemática ou simbólica (KANT, 1983, KU, p.255). Enquanto que para a primeira é dada uma intuição correspondente ao conceito, para a segunda o procedimento é apenas analógico ao que ela observa no esquematismo. No presente caso (de um fim que também é um dever) a única apresentação possível é a simbólica (ou analógica).

Todavia, um conceito apresentado (ou "esquematizado", como quer Loparic),

por analogia ou simbolizado não é 'realizado', pois o conteúdo ou a realidade objetiva que lhe é conferida preserva algo de ficcional. Sendo assim, tal conceito não pode ser usado para enunciar conhecimentos. Mesmo assim, a simbolização de conceitos da razão é de grande importância operacional, pois permite que essas idéias sejam empregadas na construção do sistema da natureza (...) bem como no sistema da liberdade, isto é, da regulamentação racional dos cursos do agir humano, que é a finalidade a que se prestam as idéias práticas sensificadas. (LOPARIC, 2003, p.490)

Tendo em mente o que dissemos antes, a possibilidade lógica do fim, ou seja, sua não contradição é respeitada (nos deveres de virtude) por se tratar de um fim ético, ou seja, um fim que é determinado por uma legislação interna que produz uma autocoerção, uma vez que o contrário seria totalmente contraditório, a saber, ser coagido a ter um fim que não fosse meu. Contudo, a possibilidade lógica deste conceito ainda não é o suficiente para garantir o conceito mesmo, sendo necessário investigar a realidade objetiva do conceito.

A realidade objetiva (ou efetividade) do conceito exige que ele seja sensificado (apresentado), como aqui não é possível uma vinculação direta entre o conceito e uma intuição correspondente, como acontece com os conceitos empíricos e puros da matemática e do entendimento, a alternativa é uma vinculação indireta mediante a apresentação (ou esquematismo) por analogia (ou simbolização). Neste caso, entre o conceito de coerção (Nötigung) e a categoria da comunidade de objetos físicos. Isto porque, "ao nos referirmos às leis do dever (não leis da natureza) e, entre estas às leis para as relações externas recíprocas dos seres humanos, nos consideramos num mundo moral (inteligível) onde, por analogia, com o mundo físico, a atração e repulsão associam os seres racionais (sobre a Terra)" (KANT, 1983, MS-T, pp.117-8). Portanto, um dever de virtude, entendido como um juízo sintético a priori, é possível apenas se puder ser garantida a ligação do conceito de fim com um objeto da sensibilidade. 
HANH, A. How are possible the virtue duties on Kant? Trans/Form/Ação, (São Paulo), v.29(2), 2006, p.115-121.

- ABSTRACT: This paper intends to show what it consists and which is the importance of investigating and offering an answer to the problem of the possibility of the virtue duties. Therefore, we will, at first, approach the problem of the possibility of the virtue duties starting from problems that refer to other a priori synthetic judgments in order to, soon after, indicate the requirements that should be accomplished by the virtue duties so that they are considered possible. This investigation is commited with Loparic's semantic interpretation.

- KEYWORDS: Kant, semantic, virtue duties.

\section{Referências bibliográficas}

KANT, I. Werke in sechs Bänden. Hrsg. von Wilhelm Weischedel. Darmstadt: Wissenschaftliche Buchgesellschaft, 1983.

LOPARIC, Z. "O Problema Fundamental da Semântica Jurídica de Kant". In: SMITH, Plínio J. e WRIGLEY, Michael B. (Orgs.). O Filósofo e a sua História. Campinas: Unicamp/CLE, 2003.

A Semântica Transcendental de Kant. Campinas: UNICAMP, Centro de Lógica, Epistemologia e História da Ciência, 2000 